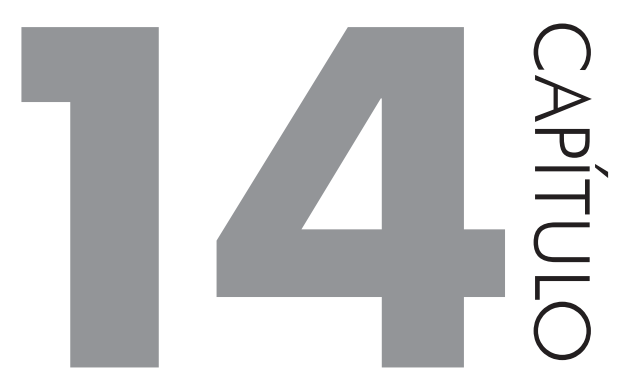

\title{
SÍNCOPE DAS VOGAIS POSTÔNICAS NÃO FINAIS: uma análise contrastiva entre variedades do Português
}

DANIELLE KELY GOMES ${ }^{1}$

\section{INTRODUÇÃO}

O vocalismo átono do Português tem sido amplamente analisado sob as mais diversas perspectivas teóricas, sobretudo no que tange a fenômenos que atuam sobre o contexto pretônico. Reflexões acerca dos demais contextos átonos são mais recentes na literatura sobre o sistema vocálico. Entende-se que o debate sobre o vocalismo átono postônico é relevante, pois as posições átonas pós-acentuais são igualmente sujeitas a fenômenos variáveis.

Neste texto, observam-se os processos de redução que atingem as vogais postônicas não finais, especialmente o apagamento dessas vogais - fenômeno que

\footnotetext{
Sou péssima para escrever agradecimentos... mas farei um esforço, pois Silvia merece todas as homenagens. Não tenho palavras mais sinceras do que o "Obrigada!”. Agradeço por me acolher sem me conhecer, quando eu - à procura de um novo rumo para minha vida acadêmica busquei sua orientação como ouvinte em um curso oferecido por ela na Pós-Graduação, em 2006. Desde então, percorri um longo trajeto, que me levou para o lugar onde sempre quis estar: no quadro de professores efetivos da UFRJ. De orientanda, passei a colega. Jamais conseguiria se não fosse por sua orientação e por seus conselhos - sempre certeiros!
} 
se enquadra no âmbito dos processos fonético-fonológicos de sincope e que regulariza os vocábulos proparoxítonos a paroxítonos. Diversos trabalhos, alinhados a diversas perspectivas teóricas - da Dialectologia clássica até as correntes fonológicas mais recentes -, atestam a vitalidade do processo no âmbito das normas do Português brasileiro, um fenômeno variável histórico com raízes no latim.

Contudo, mesmo que se esteja diante de um processo antigo na história da língua, ainda há muito sobre o que discutir acerca da síncope da vogal postônica não final. A variação na realização das vogais postônicas não finais é condicionada por fatores que estão além do nível sonoro, como - por exemplo - a produtividade dos itens proparoxítonos. Destaca-se ainda que há questões a serem pensadas quando se contrastam as variedades continentais do Português, dado que diferenças qualitativas na configuração do sistema vocálico átono promovem distinções significativas entre o Português brasileiro e o Português europeu no que concerne à aplicação da regra variável de síncope das vogais átonas não finais. Deste modo, este texto tem por objetivo adicionar mais uma questão ao debate sobre as propriedades do vocalismo átono em Português, ao estabelecer uma análise comparativa entre dados da fala fluminense e da fala metropolitana de Lisboa.

\section{O COMPORTAMENTO VARIÁVEL DAS VOGAIS POSTÔNICAS NÃO FINAIS: UMA LONGA HISTÓRIA}

A sílaba postônica não final é própria das palavras proparoxítonas, o padrão acentual menos produtivo da Língua Portuguesa. Itens lexicais proparoxítonos geralmente remetem-se a termos técnicos e pouco usuais, sendo raros os vocábulos que pertençam ao vocabulário ativo dos falantes (conjunto de palavras adquirido e usado no contexto familiar e informal, o qual incluiu apenas palavras de alta frequência e que são compartilhadas por todos os falantes da língua). A raridade dos proparoxítonos é fato bastante antigo na história da nossa língua, constatação que encontra respaldo em evidências históricas da passagem do latim para o Português.

Como decorrência desse comportamento bastante peculiar, as proparoxítonas constituem a classe acentual com o menor número de itens lexicais, conforme levantamento realizado por Araújo et al. (2007). Por isso, a excepcionalidade das proparoxítonas reflete-se nos trabalhos que se propõem a estudá-las.

Em relação à análise da regra variável de apagamento das vogais postônicas não finais, os trabalhos realizados sobre o tema também são unânimes em destacar a pressão exercida pelo tipo de segmento que está adjacente à vogal: se há a possibilidade de a consoante que acompanha a vogal átona não final ser ressilabificada, o apagamento do segmento vocálico é favorecido.

O papel do contexto fonético adjacente, na verdade, é resquício do processo atuante desde o latim e citado por Quednau (2002): o apagamento da vogal postônica não final, documentado - por exemplo - no Appendix Probbi, era favorecido 
quando as consoantes no entorno desse segmento pudessem ser ressilabificadas, seja em direção à coda da sílaba tônica, seja em direção ao onset da sílaba átona final.

Os trabalhos de cunho variacionista de que se têm notícias (CAIXETA, 1989; AMARAL, 2000; SILVA, 2006, 2010; FONSECA, 2007; LIMA, 2008; RAMOS, 2009; CHAVES, 2011; GOMES, 2012) também reafirmam que as consoantes no entorno da vogal são decisivas para a aplicação da regra de apagamento da átona não final. Entretanto, há de se ter cuidado quanto às generalizações sobre a influência do contexto fonético adjacente, sobretudo quando se contrastam as variedades continentais do Português. O Português brasileiro e o Português europeu possuem comportamentos distintos do ponto de vista fonético no que respeita à realização de sequências consonânticas: o Português Europeu permite violações, no nível fonético, aos princípios fonológicos que regem a constituição da sílaba em Português. No Português Brasileiro, por outro lado, tais violações não são produtivas.

\section{CORPORA, MÉTODO E QUESTÕES NORTEADORAS DA ANÁLISE}

A análise empreendida neste trabalho baseia-se na audição e transcrição de itens lexicais proparoxítonos recolhidos nos inquéritos que compõem os acervos dos projetos NURC-RJ (Norma Urbana Oral Culta do Rio de Janeiro), PEUL (Programa de Estudos sobre o Uso da Lingua), APERJ (Atlas Etnolinguístico dos Pescadores do Estado do Rio de Janeiro) e nas gravações relativas a Lisboa/Oeiras abrigadas no âmbito do projeto Concordância (Estudo comparado dos padrões de concordância em variedades africanas, brasileiras e europeias).

Utilizaram-se 136 entrevistas do tipo diálogo entre informante e documentador, sendo (i) 18 do Projeto NURC-RJ; (ii) 78 do Projeto APERJ; (iii) 25 entrevistas Projeto PEUL; (iv) 18 do projeto Concordância, das quais foram consideradas todas as ocorrências de proparoxítonas, em um total de 3316 dados. Para a operacionalização da análise variacionista, postularam-se condicionamentos linguísticos e sociais, investigados a partir da ferramenta estatística GoldvarbX.

Considerando-se as reflexões sobre processos que incidem sobre a sílaba postônica não final, formularam-se os seguintes princípios norteadores da análise:

a) os contextos fonéticos adjacentes à vogal postônica não final ainda se manteriam como os fatores condicionadores decisivos para a ocorrência do processo de síncope da vogal postônica não final em ambas as variedades analisadas, como um reflexo do princípio de uniformitarismo ${ }^{2}$ (LABOV, 1972, 1994);

2 Conceito tomado da Geologia, o princípio do uniformitarismo postula que "as forças que operam no presente para produzir a mudança linguística são as mesmas que operaram no passado" (LABOV, 1972). 
b) haveria diferenças quantitativas consideráveis entre as variedades brasileira e europeia no que tange a ocorrência do processo de apagamento da vogal postônica não final: o Português europeu - por conta de um processo histórico de enfraquecimento das vogais átonas - aplicaria com maior frequência a regra de apagamento; e

c) do ponto de vista dos condicionamentos sociais, a supressão da vogal postônica não final seria um fenômeno de baixo prestígio social, o que ficaria comprovado graças a atuação dos condicionamentos sexo e escolaridade: mulheres e falantes com alto grau de escolarização tenderiam a aplicar com menor frequência a regra de apagamento da vogal postônica não final.

\section{RESULTADOS}

Os índices gerais de aplicação da regra de apagamento da vogal postônica não final revelam duas tendências bastante particulares, que merecem considerações: por um lado, não há diferenças quantitativas significativas quando se comparam os três conjuntos de dados relativos às normas fluminenses; por outro, quando se contrastam esses resultados com os índices encontrados na amostra representativa da norma da zona metropolitana de Lisboa, observa-se que, nos dados europeus, os índices de aplicação são consideravelmente maiores. A Tabela 1 - a seguir - evidencia os percentuais gerais para a ocorrência do fenômeno em cada variedade analisada.

Tabela 1 Distribuição dos dados por amostra.

\begin{tabular}{|c|c|c|}
\hline & AMOSTRA & OCORRÊNCIAS \\
\hline \multirow{3}{*}{$\begin{array}{l}\text { Normas fluminenses } \\
\text { (Português Brasileiro) }\end{array}$} & $\begin{array}{l}\text { NURC } \\
\text { (fala culta urbana) }\end{array}$ & $95 / 816=11 \%$ \\
\hline & $\begin{array}{l}\text { PEUL } \\
\text { (fala popular urbana) }\end{array}$ & $192 / 1317=14 \%$ \\
\hline & $\begin{array}{l}\text { APERJ } \\
\text { (fala rural popular) }\end{array}$ & $130 / 855=15 \%$ \\
\hline $\begin{array}{l}\text { Norma metropolitana de Lisboa } \\
\text { (Português Europeu) }\end{array}$ & $\begin{array}{l}\text { Concordância } \\
\text { (fala urbana - culta e popular) }\end{array}$ & $167 / 328=49 \%$ \\
\hline
\end{tabular}

Entre as variáveis postuladas para a investigação do fenômeno em foco, revelaram-se estatisticamente relevantes as elencadas no Quadro a seguir. Os resul- 
tados são apresentados por amostra analisada, uma vez que o perfil sociolinguístico de cada corpus não permitia o tratamento em conjunto dos dados.

Quadro 1 Variáveis atuantes no apagamento da vogal postônica não final.

\begin{tabular}{|c|c|c|c|}
\hline NURC & PEUL & APERJ & CONCORDÂNCIA \\
\hline $\begin{array}{l}\text { Modo de articulação da } \\
\text { consoante seguinte } \\
\text { Faixa etária }\end{array}$ & $\begin{array}{l}\text { Ponto de articulação da } \\
\text { consoante seguinte } \\
\text { Modo de articulação da } \\
\text { consoante seguinte } \\
\text { Ponto de articulação da } \\
\text { consoante precedente } \\
\text { Ponto de articulação da } \\
\text { vogal postônica não final } \\
\text { Dimensão do vocábulo } \\
\text { Modo de articulação da } \\
\text { consoante precedente } \\
\text { Faixa Etária } \\
\text { Sexo }\end{array}$ & $\begin{array}{l}\text { Ponto de articulação da } \\
\text { vogal postônica não final } \\
\text { Modo de articulação da } \\
\text { consoante seguinte } \\
\text { Ponto de articulação da } \\
\text { consoante precedente } \\
\text { Modo de articulação da } \\
\text { consoante precedente } \\
\text { Escolaridade }\end{array}$ & $\begin{array}{l}\text { Modo de articulação da } \\
\text { consoante precedente } \\
\text { Modo de articulação da } \\
\text { consoante seguinte } \\
\text { Dimensão do vocábulo }\end{array}$ \\
\hline $\begin{array}{l}\text { Input inicial: .11 } \\
\text { Input de seleção: .07 } \\
\text { Sig.: .000 }\end{array}$ & $\begin{array}{l}\text { Input inicial: .14 } \\
\text { Input de seleção: .04 } \\
\text { Sig.: .000 }\end{array}$ & $\begin{array}{l}\text { Input inicial: .15 } \\
\text { Input de seleção: .07 } \\
\text { Sig.: .014 }\end{array}$ & $\begin{array}{l}\text { Input inicial: . } 49 \\
\text { Input de seleção: .56 } \\
\text { Sig.: .015 }\end{array}$ \\
\hline
\end{tabular}

Os resultados expostos no quadro anterior deixam evidente a vitalidade do contexto fônico adjacente para a ocorrência do processo de síncope da vogal postônica não final em todas as normas investigadas. Assim, para efeito da comparação entre as variedades no que respeita à atuação de um mesmo condicionamento fonético-fonológico, as análises apresentadas neste texto vão considerar o papel das consoantes precedente e subsequente à vogal postônica não final para a aplicação da regra de apagamento. Para uma reflexão sobre o valor social da variante com apagamento da vogal, em um segundo momento fazem-se apreciações quanto à atuação dos condicionamentos extralinguísticos.

\subsection{O efeito das consoantes adjacentes à postônica não final}

Esperava-se que os contextos que favorecessem a ressilabificação das consoantes adjacentes à vogal postônica não final favorecessem a aplicação da regra de apagamento. $\mathrm{Na}$ Tabela 2 , a seguir, onde estão expressos os índices percentuais e os pesos relativos para a atuação das consoantes precedentes à vogal, observa-se que tal princípio se confirma. 
Tabela 2 Efeito do modo de articulação da consoante precedente para a síncope da vogal postônica não final.

\begin{tabular}{|c|c|c|c|c|c|c|c|c|}
\hline \multirow{2}{*}{ CONTEXTO } & \multicolumn{2}{|l|}{ NURC } & \multicolumn{2}{|l|}{ PEUL } & \multicolumn{2}{|l|}{ APERJ } & \multicolumn{2}{|c|}{ CONCORDÂNCIA } \\
\hline & OCO & PR. & oco & PR. & oco & PR. & OCO & PR \\
\hline $\begin{array}{l}\text { Oclusivas e } \\
\text { Fricativas } \\
\text { (bêbado) }\end{array}$ & $82 / 587=13 \%$ & $(.52)$ & $116 / 849=13 \%$ & .52 & $125 / 693=18 \%$ & .61 & $140 / 212=66 \%$ & .58 \\
\hline $\begin{array}{l}\text { Nasais } \\
\text { (ônibus) }\end{array}$ & $12 / 128=9 \%$ & $(.40)$ & $73 / 296=24 \%$ & .64 & $4 / 114=3 \%$ & .04 & $15 / 43=34 \%$ & .18 \\
\hline $\begin{array}{l}\text { Laterais } \\
\text { (có/ica) }\end{array}$ & $0 / 20=0 \%$ & - & $1 / 58=1 \%$ & .06 & $0 / 34=0 \%$ & - & \multirow{2}{*}{$4 / 13=30 \%$} & \multirow{2}{*}{.25} \\
\hline $\begin{array}{l}\text { Vibrantes } \\
\text { (América) }\end{array}$ & $0 / 46=0 \%$ & - & $1 / 40=2 \%$ & .09 & $0 / 11=0 \%$ & - & & \\
\hline & Sig.: .060 & & $\begin{array}{l}\text { Input: .04 } \\
\text { Sig.: .000 }\end{array}$ & & $\begin{array}{l}\text { Input: .07 } \\
\text { Sig.: .014 }\end{array}$ & & $\begin{array}{l}\text { Input: } .56 \\
\text { Sig: .015 }\end{array}$ & \\
\hline
\end{tabular}

No corpus APERJ, o apagamento é altamente favorecido quando a queda da vogal postônica leva à formação de onsets complexos na sílaba átona final, já que são as consoantes precedentes oclusivas e fricativas as que se mostraram mais relevantes (.61). Observa-se que as líquidas não atuam nesse sentido, ocorrendo praticamente o mesmo com as nasais (.04). Já os dados da amostra PEUL mostram as nasais como as mais propícias ao processo (.64), seguidas das oclusivas e fricativas (.52), resultado que destoa dos demais corpora e que, certamente, se deve às diversas ocorrências da palavra ônibus (44 apagamentos em 93 ocorrências).

Para os dados do Português europeu, nota-se que os índices expressos na Tabela 2 refletem a tendência observada para as variedades populares do Português brasileiro: a presença de consoantes oclusivas e fricativas no onset da sílaba postônica não final tende a favorecer o apagamento da vogal átona medial (.58). As consoantes nasais e líquidas atuam como bloqueadoras da regra (.25 e .18, respectivamente).

Quando se comparam os resultados verificados para o corpus NURC (que não foram apontados como relevantes pela análise estatística) com os das demais variedades analisadas, percebe-se que há uma convergência entre as normas culta e rural fluminenses no que concerne à atuação da varável consoante precedente à vogal postônica não final: as obstruintes não nasais se revelam como favorecedoras e as nasais atuam como inibidoras do processo. Todavia, a diferença entre os con- 
textos nos dados do NURC não é expressiva (.52 contra .40), o que - de certa forma - impede uma apreciação mais abrangente da variável no âmbito da fala culta.

No que respeita à atuação das consoantes subsequentes à vogal postônica não final, esperava-se que a presença de consoantes líquidas no ataque da sílaba átona final favoreceria a queda da vogal postônica, uma vez que tais consoantes podem tanto se anexar à coda da sílaba tônica - formando o padrão CVC nesse contexto -, quanto figurar como segundo elemento de um ataque complexo, desde que haja no ataque da sílaba postônica não final uma consoante obstruinte (oclusivas ou fricativas labiais). Na Tabela 3, logo a seguir, estão expressos os índices percentuais e os valores relativos para a variável consoante subsequente.

Tabela 3 Efeito do modo de articulação da consoante seguinte para a síncope da vogal postônica não final.

\begin{tabular}{|c|c|c|c|c|c|c|c|c|}
\hline \multirow{2}{*}{ CONTEXTO } & \multicolumn{2}{|l|}{ NURC } & \multicolumn{2}{|l|}{ PEUL } & \multicolumn{2}{|l|}{ APERJ } & \multicolumn{2}{|c|}{ CONCORDÂNCIA } \\
\hline & oco & PR & oco & P R & oco & P R & OCO & P R \\
\hline $\begin{array}{l}\text { Oclusivas e } \\
\text { Fricativas } \\
\text { (época) }\end{array}$ & $24 / 498=4 \%$ & .36 & $74 / 865=8 \%$ & .50 & $73 / 567=12 \%$ & .47 & $96 / 220=43 \%$ & .41 \\
\hline $\begin{array}{l}\text { Nasais } \\
\text { (mínimo) }\end{array}$ & $14 / 162=8 \%$ & .50 & $41 / 268=15 \%$ & .31 & $1 / 72=1 \%$ & .08 & $47 / 84=55 \%$ & .58 \\
\hline $\begin{array}{l}\text { Lateral } \\
\text { (ócu/os) }\end{array}$ & $47 / 77=61 \%$ & .95 & $54 / 95=56 \%$ & .67 & $12 / 68=22 \%$ & .57 & $9 / 11=81 \%$ & .76 \\
\hline $\begin{array}{l}\text { Vibrante } \\
\text { (abóbora) }\end{array}$ & $9 / 60=15 \%$ & .65 & $17 / 78=21 \%$ & .80 & $41 / 133=30 \%$ & .83 & $9 / 12=75 \%$ & .94 \\
\hline & $\begin{array}{l}\text { Input: .07 } \\
\text { Sig.: .000 }\end{array}$ & & $\begin{array}{l}\text { Input. .04 } \\
\text { Sig.: .000 }\end{array}$ & & $\begin{array}{l}\text { Input. } .07 \\
\text { Sig.: .014 }\end{array}$ & & $\begin{array}{l}\text { Input. } 056 \\
\text { Sig.: .015 }\end{array}$ & \\
\hline
\end{tabular}

As consoantes lateral e vibrante, nas quatro amostras consideradas, atuam no sentido de favorecer a síncope da vogal postônica não final, embora se observem diferenças entre os conjuntos de dados quanto aos pesos relativos e à hierarquia dos fatores. O corpus NURC se diferencia dos demais, no sentido de que a lateral, com peso relativo .95 , se mostra mais significativa para o cancelamento do que a vibrante, que é a variante mais saliente nos outros três corpora (PEUL, .80; APERJ, .83; Concordância, .94). Os resultados sugerem que o apagamento da vogal postônica não final é fortemente condicionado por licenciamentos na estrutura fonotática da língua, mesmo na norma lusitana, que - conforme consi- 
derações feitas anteriormente - permite no nível fonético a violação dos princípios fonológicos de constituição da sílaba.

\subsubsection{Reflexões sobre $a$ atuação dos condicionamentos sociais}

O objetivo maior de um trabalho sociolinguístico é verificar de que forma a constituição da comunidade de fala em análise interage com aspectos relativos aos usos linguísticos dos indivíduos. Neste trabalho, esperava-se que o processo de apagamento da vogal postônica não final fosse alvo de restrições sociais tanto nos dados relativos às normas fluminenses quanto à norma metropolitana de Lisboa. Entretanto, notou-se que o fenômeno, que culmina na regularização das proparoxítonas ao padrão acentual default em Português, não encontra restrições sociais na comunidade de fala portuguesa. A Tabela 4 , a seguir, revela que no âmbito dos dados brasileiros há sempre ao menos um condicionante social a interagir com fatores linguísticos para a aplicação da regra de síncope da postônica não final.

Tabela 4 Efeito dos condicionamentos sociais - fala fluminense.

\begin{tabular}{|c|c|c|c|c|}
\hline CORPUS & & OCO & P. $\mathbf{R}$ & \\
\hline \multirow{3}{*}{$\begin{array}{l}\text { NURC } \\
\text { Faixa Etária }\end{array}$} & $\begin{array}{l}\text { Faixa } 1 \\
\text { (18 a } 35 \text { anos) }\end{array}$ & $38 / 261=14 \%$ & .64 & \multirow{3}{*}{$\begin{array}{l}\text { Input: .07 } \\
\text { Sig.: .000 }\end{array}$} \\
\hline & $\begin{array}{l}\text { Faixa } 2 \\
\text { (36 a } 55 \text { anos) }\end{array}$ & $27 / 183=14 \%$ & .57 & \\
\hline & $\begin{array}{l}\text { Faixa } 3 \\
\text { (mais de } 56 \text { anos) }\end{array}$ & $30 / 342=8 \%$ & .36 & \\
\hline \multicolumn{5}{|l|}{ PEUL } \\
\hline \multirow{3}{*}{ Faixa Etária } & $\begin{array}{l}\text { Faixa } 1 \\
\text { (18 a } 35 \text { anos) }\end{array}$ & $20 / 304=6 \%$ & .27 & \multirow{3}{*}{$\begin{array}{l}\text { Input: .04 } \\
\text { Sig.: .000 }\end{array}$} \\
\hline & $\begin{array}{l}\text { Faixa } 2 \\
\text { (36 a } 55 \text { anos) }\end{array}$ & $80 / 528=15 \%$ & .50 & \\
\hline & $\begin{array}{l}\text { Faixa } 3 \\
\text { (mais de } 56 \text { anos) }\end{array}$ & $92 / 485=18 \%$ & .64 & \\
\hline \multirow{2}{*}{ Sexo } & Homens & $113 / 658=17 \%$ & .62 & \multirow{2}{*}{$\begin{array}{l}\text { Input: .04 } \\
\text { Sig.: .000 }\end{array}$} \\
\hline & Mulheres & $79 / 659=11 \%$ & .37 & \\
\hline \multirow{2}{*}{$\begin{array}{l}\text { APERJ } \\
\text { Escolaridade }\end{array}$} & Analfabetos & $75 / 323=23 \%$ & .67 & \multirow{2}{*}{$\begin{array}{l}\text { Input: .07 } \\
\text { Sig.: } 014\end{array}$} \\
\hline & Alfabetizados & $55 / 526=10 \%$ & .38 & \\
\hline
\end{tabular}


Com relação à atuação da variável faixa etária, condicionamento atuante tanto na fala culta quanto na fala popular da capital fluminense, duas tendências opostas são observadas.

Os resultados verificados no corpus NURC mostram que os falantes das faixas etárias mais jovens aplicam a regra de apagamento da vogal átona medial com mais frequência do que os da faixa etária mais alta. Os índices probabilísticos confirmam o decréscimo na aplicação da regra: os valores dos pesos relativos diminuem à medida que se avança pelas faixas etárias $(.64, .57$ e .36 para as faixas 1,2 e 3, respectivamente). Tal tendência pode ser reflexo de um menor conservadorismo dos indivíduos cultos mais jovens, mais propensos a formas que fujam ao padrão.

No que se refere à amostra PEUL, os resultados expostos na tabela parecem indicar que os falantes mais velhos, com mais de 56 anos de idade, realizam muito mais formas sincopadas (.64) do que os falantes da faixa mais jovem. (.50 para faixa 2 e .27 para faixa 1). Percebe-se, ainda, que a faixa mais jovem utiliza mais as formas padrão, o que pode ser indício de que o processo de regularização dos vocábulos proparoxítonos em paroxítonos é uma variável sem prestígio social nesse grupo.

Quanto à atuação do condicionamento sexo, relevante para o corpus PEUL, pode-se inferir que, no âmbito da fala popular urbana fluminense, estamos diante de uma variável sem prestígio social. Quando a variação não é um indício de um fenômeno de mudança em progresso, como mostram os resultados na perspectiva do tempo aparente, as mulheres tendem a utilizar as formas de prestígio muito mais do que os homens. Os resultados comprovam a primeira tendência com relação ao papel da variável sexo, descrito anteriormente: os homens favorecem as formas com apagamento mais do que as mulheres (.62 e .37, respectivamente).

Sobre a atuação da variável escolaridade, relevante para o corpus APERJ representativo da fala rural masculina fluminense, percebe-se que o apagamento da vogal postônica não final é mais produtivo na fala dos analfabetos do que na dos escolarizados (.67 contra .38). Tal resultado confirma a hipótese postulada, já que os falantes analfabetos, por não terem contato com a modalidade escrita, tendem a apresentar mais em sua fala as formas desprestigiadas socialmente.

Quanto aos resultados relativos ao Português europeu, representado aqui pela norma metropolitana de Lisboa, cabe a pergunta: por que não há atuação de condicionamentos sociais na aplicação da regra de síncope da vogal postônica não final nesse conjunto de dados? Esboça-se uma possível explicação a seguir.

\section{UMA POSSÍVEL EXPLICAÇÃO PARA AS DIVERGÊNCIAS ENTRE VARIEDADES}

Uma possível explicação para as diferenças entre as normas fluminense e lisboeta no que se refere à produtividade da regra de síncope das postônicas não 
finais pode residir na relação entre os processos de alteamento e apagamento, considerando a ocorrência dos fenômenos tanto no Português brasileiro quanto na variedade europeia.

É notória a maior produtividade do fenômeno de apagamento quando se confrontam as duas variedades continentais. No âmbito do Português brasileiro, os índices gerais de aplicação da regra são relativamente próximos (inputs .07 para o NURC, .04 para o PEUL e .07 para o APERJ - conforme evidenciado na Tabela 2), e revelam uma baixa ocorrência do processo. Uma provável explicação para o comportamento da variedade brasileira pode estar vinculada ao fato de, nos contextos átonos do $\mathrm{PB}$, ainda ser mais produtiva a regra de alteamento das vogais médias, conforme salientam diversos trabalhos (CAMARA JR., 1979; WETZELS, 1992; BISOL, 2003; BISOL E MAGALHÃES, 2004; DE PAULA, 2010, 2015). Assim, a variedade brasileira, em suas diversas normas, opta por manter a vogal postônica não final, variando apenas quando nesse contexto se encontra uma vogal média, que pode ser alvo do processo de alteamento.

Tal hipótese leva à associação entre os processos de apagamento ao de alteamento: no $\mathrm{PB}$, o apagamento em contexto postônico não final talvez seja pouco produtivo porque se observa variação na realização das vogais médias e altas nos contextos átonos. No PE, o processo de alteamento, em contexto pretônico, "se generalizou durante a primeira metade do século XVIII", constituindo uma "mudança paradigmática, fonológica (não condicionada)" (CASTRO, 1991, p. 259). Sincronicamente, em contexto postônico não final, só se observam, como mostram Mateus e d'Andrade (2000), as vogais [r], [i] e [u], todas realizações altas. No Português brasileiro, mantém-se um quadro de variação estável nos contextos átonos; no PE europeu, parece estar havendo uma tendência ao apagamento.

Assim, o apagamento da vogal postônica não final no PE - por ser significativamente frequente (input .56) e corresponder a um processo que não se restringe a essa posição, atingindo outros contextos átonos - não seria marcado socialmente. Os resultados das análises aqui realizadas, de certa forma, refletem esse quadro: na análise referente ao PE, não houve interação, só variáveis estruturais se mostraram salientes; nas referentes ao $\mathrm{PB}$, pelo menos uma variável social mostrou-se relevante (corpus NURC: faixa etária; corpus PEUL: sexo e faixa etária; corpus APERJ: escolaridade).

\section{CONSIDERAÇÕES FINAIS}

Neste trabalho, observaram-se convergências e divergências quantitativas consideráveis entre a fala fluminense e a norma metropolitana de Lisboa em relação à aplicação da regra de síncope da vogal postônica não final. No que tange às divergências, notou-se que: 
1. os dados lisboetas revelam que, nesta variedade, há uma alta incidência do apagamento da átona não final;

2. os dados fluminenses - independentemente da norma sob análise - revelam uma relativa uniformidade nos índices gerais de ocorrência do fenômeno, que indicam para uma baixa produtividade do processo de apagamento da vogal postônica não final.

Entre as convergências, observou-se que, quanto à atuação dos condicionamentos fonéticos, há correlação - tanto nos dados brasileiros quanto portugueses - entre o apagamento da vogal postônica não final e a ressilabificação das consoantes que a acompanham, reflexo de um princípio que atua desde o latim vulgar: quando a consoante que acompanha a postônica não final pode ser ressilabificada - principalmente em direção ao onset da sílaba átona final, há semelhanças consideráveis entre as variedades aqui analisadas.

Se há uma relativa convergência qualitativa entre as variedades no que diz respeito à relação entre contexto fonético precedente/subsequente e a manutenção/ síncope da vogal postônica não final, de que forma é possível explicar as diferenças quantitativas consideráveis entre as normas continentais em análise? Uma possível justificativa pode residir nas diferenças na constituição do sistema vocálico átono do Português brasileiro e do Português europeu. As particularidades das vogais átonas de cada variedade podem justificar as diferenças quanto à interação entre os condicionamentos linguísticos e sociais para a aplicação da regra nos dados:

1. na variedade brasileira, o apagamento de vogais é objeto de valoração social - o processo de alteamento ainda é mais frequente; assim, a aplicação da regra de apagamento estará condicionada a um ou mais fator(es) extralinguístico(s);

2. por seu turno, a variedade europeia praticamente concluiu o processo de alteamento no contexto pretônico, expandindo a atuação da regra fonológica de alteamento para os demais contextos vocálicos átonos. $\mathrm{O}$ apagamento das vogais constituiria uma etapa seguinte ao processo de mudança nos sistemas não acentuados. Daí, a alta incidência de síncope nos dados relativos ao Português Europeu.

\section{REFERÊNCIAS BIBLIOGRÁFICAS}

AMARAL, Marisa Porto do. As proparoxítonas: teoria e variação. 2000. Tese (Doutorado em Letras) - Faculdade de Letras, Pontifícia Universidade Católica do Rio Grande do Sul, Porto Alegre, 2000.

ARAÚJO, Gabriel Antunes de et al. "As proparoxítonas e o sistema acentual do Português”. In: ARAÚJO, Gabriel Antunes (org.). O acento em Português: abordagens fonológicas. São Paulo: Parábola, 2000, p. 37-60. 
CAIXETA, Valmir. Descrição e análise da redução das palavras proparoxitonas. 1989. Dissertação (Mestrado em Linguística) - Faculdade de Letras, Universidade Federal do Rio de Janeiro, Rio de Janeiro, 1989.

CASTRO, Ivo. Curso de história da Língua Portuguesa. Lisboa: Universidade Aberta, 1991.

CHAVES. Raquel Gomes. A redução de proparoxitonos na fala do Sul do Brasil. 2011. Dissertação (Mestrado em Linguística) - Pontifícia Universidade Católica do Rio Grande do Sul, Porto Alegre, 2011.

DE PAULA, Alessandra. Vogais médias postônicas na fala do Estado do Rio de Janeiro. 2010. Dissertação (Mestrado em Letras Vernáculas) - Faculdade de Letras, Universidade Federal do Rio de Janeiro, Rio de Janeiro, 2010.

- Variação e mudança no vocalismo postônico medial em Português. 2015. Tese (Doutorado em Letras Vernáculas) - Faculdade de Letras, Universidade Federal do Rio de Janeiro, 2015.

FONSECA, Simone Meckler. O problema das proparoxitonas: a perda da vogal postônica. 2007. Dissertação (Mestrado em Linguística) - Universidade Federal de Juiz de Fora, Juiz de Fora, 2007.

GOMES, Danielle Kely. Síncope em proparoxitonas: um estudo contrastivo entre o Português brasileiro e o Português europeu. 2012. Tese (Doutorado em Letras Vernáculas) - Faculdade de Letras, Universidade Federal do Rio de Janeiro. 2012.

LIMA, Giselly de Oliveira. O efeito da síncope em proparoxitonas: uma análise fonológica e variacionista com dados do sudoeste goiano. 2008. Dissertação (Mestrado em Linguística) - Universidade Federal de Uberlândia, Uberlândia, 2008.

MAGALHÃES, José Sueli. O plano multidimensional do acento na Teoria da Otimidade. 2004. Tese (Doutorado em Letras) - Faculdade de Letras, Pontifícia Universidade Católica do Rio Grande do Sul, Porto Alegre, 2004.

MATEUS, Maria Helena Mira e D’ANDRADE, Ernesto. The Phonology of Portuguese. Oxford: Oxford University Press, 2000.

QUEDNAU, Laura Rosane. A síncope e seus efeitos no Latim e no Português Arcaico. In: BISOL, Leda; BRESCANCINI, Claudia (orgs.). Fonologia e Variação: recortes do Português brasileiro. Porto Alegre: EDIPUCRS, 2002, p. 79-97.

RAMOS, Adriana Perpétua. Descrição das vogais postônicas não finais na variedade do Noroeste Paulista. 2009. Dissertação (Mestrado em Linguística) - Unesp, São José do Rio Preto, 2009.

SILVA, André Pedro. Supressão da vogal átona postônica não final: uma tendência das proparoxítonas na Língua Portuguesa com evidências no falar sapeense. 2006. Dissertação (Mestrado em Língua Portuguesa) - UFPB, João Pessoa, 2006.

. Vogais postônicas não finais: do sistema ao uso. João Pessoa, 2010. Tese (Doutorado em Linguística) - UFPB, João Pessoa, 2010. 